\title{
DESAFIO PRÁTICO DO CURSO TÉCNICO EM LOGÍSTICA EAD: SOLUÇÕES PARA CASOS REAIS DE GARGALOS LOGÍSTICOS.
}

\author{
GOIÂNIA/GO JUNHO/2018
}

\author{
Fabricio Leandro Costa e Silva - SENAI/GO - fabriciosilva.senai@sistemafieg.org.br \\ Tipo: Relato de Experiência Inovadora (EI) \\ Categoria: Métodos e Tecnologias \\ Setor Educacional: EDUCAÇÃO MÉDIA E TECNOLÓGICA
}

\begin{abstract}
RESUMO
O presente artigo aborda uma experiência de ensino fundamentada na identificação de uma situaçãoproblema no processo logístico de uma determinada empresa. Seu estudo e a definição de uma proposta técnica-financeira para implementação da solução atende à metodologia SENAI de Educação Profissional que, por sua vez, se baseia no desenvolvimento de competências.

O estudante do curso técnico em logística EaD é direcionado a identificar e resolver um problema da empresa por meio da operacionalização dos conteúdos estudados a distância sob a mediação do docente. Esta estratégia tem demonstrado a importância do estudante lidar com situações-problema que se assemelham àquelas que ele irá enfrentar em sua vida profissional, tornando a aprendizagem mais ativa e significativa. Além disso, o projeto tem se caracterizado como uma importante estratégia de inovação tecnológica por meio de sua inserção nas empresas.
\end{abstract}

Palavras-chave: Situação-problema. Logística. Solução. Estratégia. 


\section{1 - Introdução}

O processo de ensino e aprendizagem no Brasil se caracteriza essencialmente no modelo centrado no docente, onde o principal papel é ensinar conteúdos, e ao estudante cabe absorvê-los e ponto final. Este padrão foi denominado por Paulo Freire (1996) de educação bancária e criticado como única estratégia de ensino na formação de pessoas capazes de intervir em sua própria história de vida. Nesse sentido, é importante ressaltar que vivenciamos uma sociedade cujos avanços científicos e tecnológicos interferem diretamente em nosso exercício ativo e consciente da cidadania. Desta maneira as obtenções de competências sociais, organizativas e metodológicas tornam-se essenciais para que o profissional/cidadão possa dar conta dessa nova realidade.

$\mathrm{Na}$ contramão desse aspecto, o processo de ensino-aprendizagem utilizado neste caso, permite o estudo de contextos que desenvolvam habilidades de investigação e interação em grupo para uma solução prática específica e in loco. Assim, os desafios práticos foram preparados visando o aprendizado do estudante e não apenas como reprodução de um fenômeno ou verificação de uma lei teórica, como ocorre em um laboratório tradicional, em que um grupo de estudantes segue instruções de um roteiro estabelecido pelo professor, com o objetivo de testar conceitos ensinados em sala de aula (Borges, 2002). Ou seja, trata-se de uma experimentação problematizadora do cotidiano logístico da empresa aplicado em um curso técnico a distância no SENAI - Departamento Regional de Goiás.

\section{2 - Metodologia}

Este estudo apresenta uma situação problema real identificada em um supermercado pertencente a uma grande rede varejista em Niquelândia/GO que serviu como contexto para implementação do projeto final dos estudantes de uma turma do curso Técnico em Logística do SENAI desenvolvido na modalidade a distância com carga horário total de 960 horas.

A Metodologia SENAI de Educação Profissional tem como alvo o desenvolvimento de competências correspondentes à mobilização de conhecimentos, habilidades e atitudes necessários ao desempenho de funções e atividades típicas de uma ocupação, segundo padrões de qualidade e produtividade requeridos pela natureza do trabalho.

Desta maneira, para que a aplicação deste método seja exitosa, deve-se incluir além das habilidades técnicas requeridas para o exercício de uma atividade concreta, um conjunto de comportamentos interativos, como tomada de decisão, comunicação com o 
ambiente, organização do trabalho e outros necessários ao pleno desempenho profissional em um determinado campo de atuação.

Essas competências são colocadas à prova no momento em que são lançados os desafios que é a proposição de uma atividade nova, no sentido de ser diferente das que o estudante já realizou.

Isso não quer dizer que cada solução deva ser inédita. Deve, sim, ser fruto de reflexão, tomada de decisão e da realização de uma ou mais atividades. Não pode ter uma resposta pronta que pode ser acessada ou lembrada.

Um desafio deve desequilibrar o aluno, obrigando-o a buscar soluções inusitadas e novos conhecimentos (Perrenoud, 1999). Logo, o estabelecimento de padrões de desempenho devem servir como evidência válida para demonstrar a performance definida e/ou esperada do estudante.

Esse processo realiza a transposição das informações do mundo do trabalho para o mundo da educação, traduzindo pedagogicamente as competências do perfil profissional estabelecido para o curso.

Deste modo, durante o desenvolvimento do penúltimo módulo do curso, a coordenação do curso articulou, em conjunto com a equipe pedagógica e técnica da Escola SENAI Niquelândia, uma parceria com esta empresa, onde foram acordadas as sequências de etapas: i) os estudantes serão organizados em cinco grupos com no máximo seis integrantes; ii) elaboração de um cronograma de visitas técnicas ao estabelecimento; iii) identificação dos oportunidades de melhoria nos processos logísticos (continuamente mediados pelo corpo docente); iv) escolha do problema/oportunidades de melhoria pelos grupos; v) elaboração e apresentação do plano de ação de cada grupo à gestão da empresa; vi) construção da proposta de solução; vii) apresentação final das propostas ao corpo docente, técnico e pedagógico do SENAI (Núcleo de Educação a Distância e Unidade Operacional) em conjunto com a gestão da empresa.

É importante ressaltar que, ao longo do desenvolvimento do projeto, deve-se realizar o controle de qualidade que permite avaliar a coerência, a consistência e a validade de cada um dos produtos obtidos nas diversas fases do trabalho. Para tanto, serão usadas as Listas de Verificação apresentadas ao final de cada etapa.

A partir daí os estudantes deverão refletir as causas do problema/oportunidade de melhoria identificado, elaborando pontos essenciais que deverão ser pesquisados e 
estudados, relacionando-os com os conhecimentos já adquiridos durante o curso, além de planejar a etapa seguinte - da teorização. Nesta etapa, os estudantes se organizam para buscar informações críticas para a solução do problema, analisando e registrando as contribuições pertinentes, permitindo o desenvolvimento da etapa seguinte - a da solução -, em que os estudantes preparam possíveis soluções para o problema.

Partindo de situações problemáticas reais, o estudante buscará o conhecimento necessário para entendê-la, seja mediante pesquisa bibliográfica, discussões em grupo ou diálogo com professores de sua e de outras áreas de conhecimento, além de técnicos envolvidos no assunto, como o próprio gestor da área da empresa parceira.

Na última etapa - aplicação técnica -, os estudantes colocam em prática as proposições para o problema por meio da construção de maquetes, simulando uma situação real. A complexidade para a montagem, execução e solução dos problemas são etapas importantes para que o estudante exercite sua capacidade criativa, autonomia e iniciativa para conduzir e realizar tarefas e compartilhamento de conhecimentos com os colegas na execução das atividades, que os ajudarão no mercado de trabalho.

De acordo com Freire, "quanto mais se problematizam os educandos como seres no mundo e com o mundo, tanto mais se sentirão desafiados. Tão mais desafiados, quanto mais obrigados a responder ao desafio" (Freire, 1970).

\section{3 - Resultados e Discussões}

Alguns exemplos de oportunidade de melhoria foram observados durante a construção da parceria e, inicialmente, destacados como críticos pela gestão da empresa. A Figura 1 apresenta a armazenagem de materiais sem a utilização e classificação das embalagens e tipos de produtos; A Figura 2 exibe a armazenagem de produtos nocivos à saúde em contato com outros produtos; A Figura 3 demonstra parte do layout do estoque sem aparente sinalização para movimentação de materiais e, sobretudo, a ausência de endereçamento.

Figura 1 - alocação de materiais 


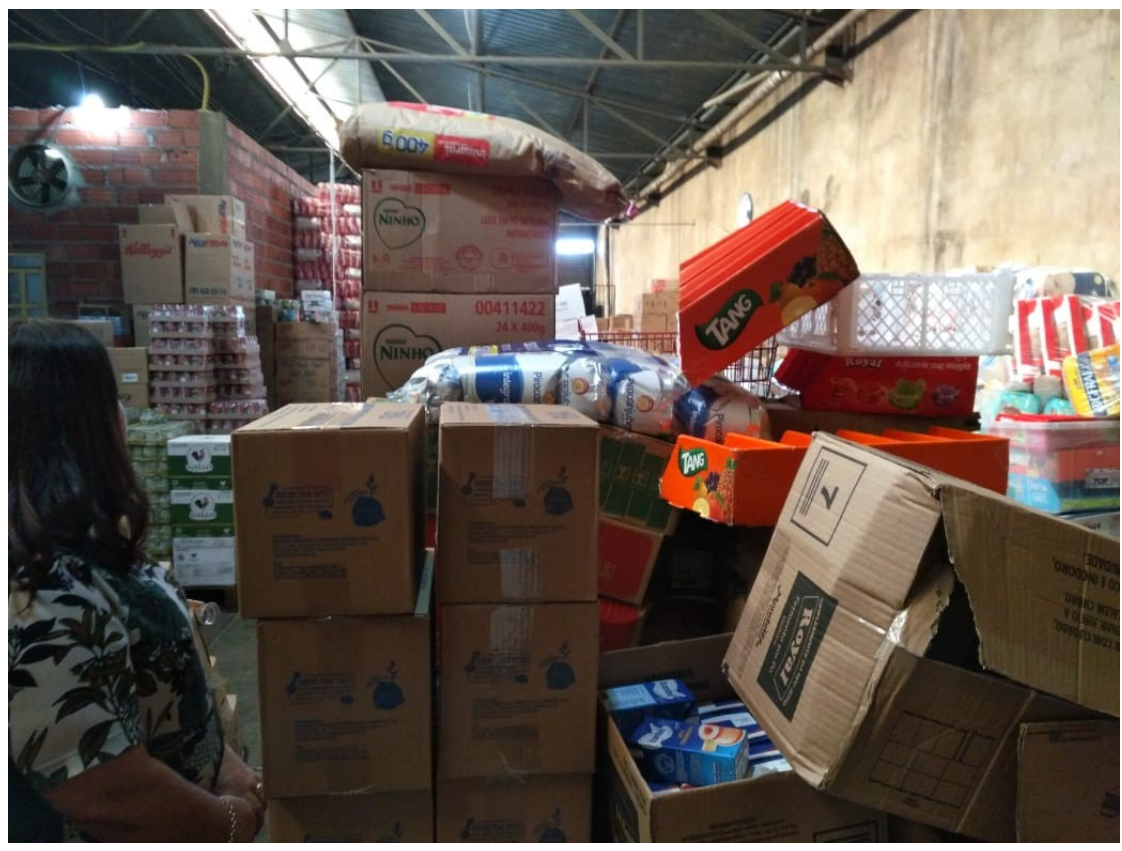

Fonte: Arquivo pessoal.

Figura 2 - armazenagem de produtos perigosos

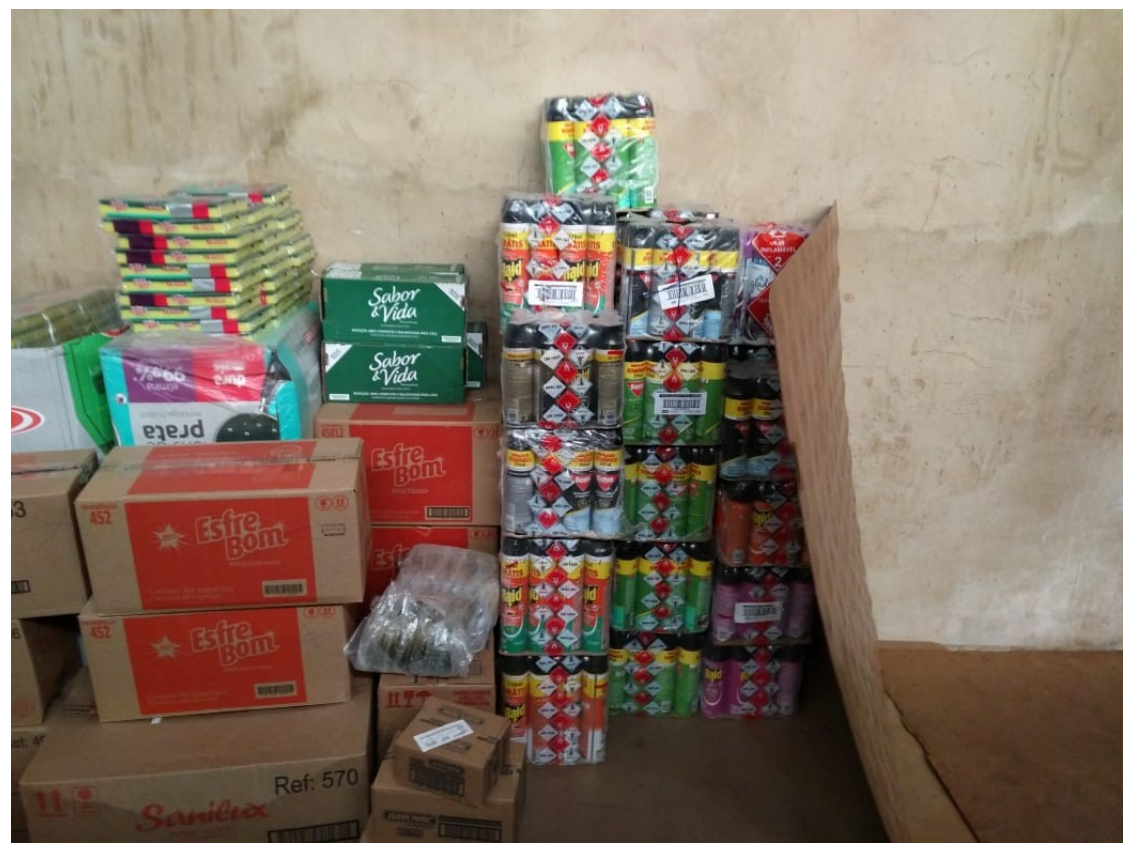

Fonte: Arquivo pessoal.

Figura 3 - Layout 


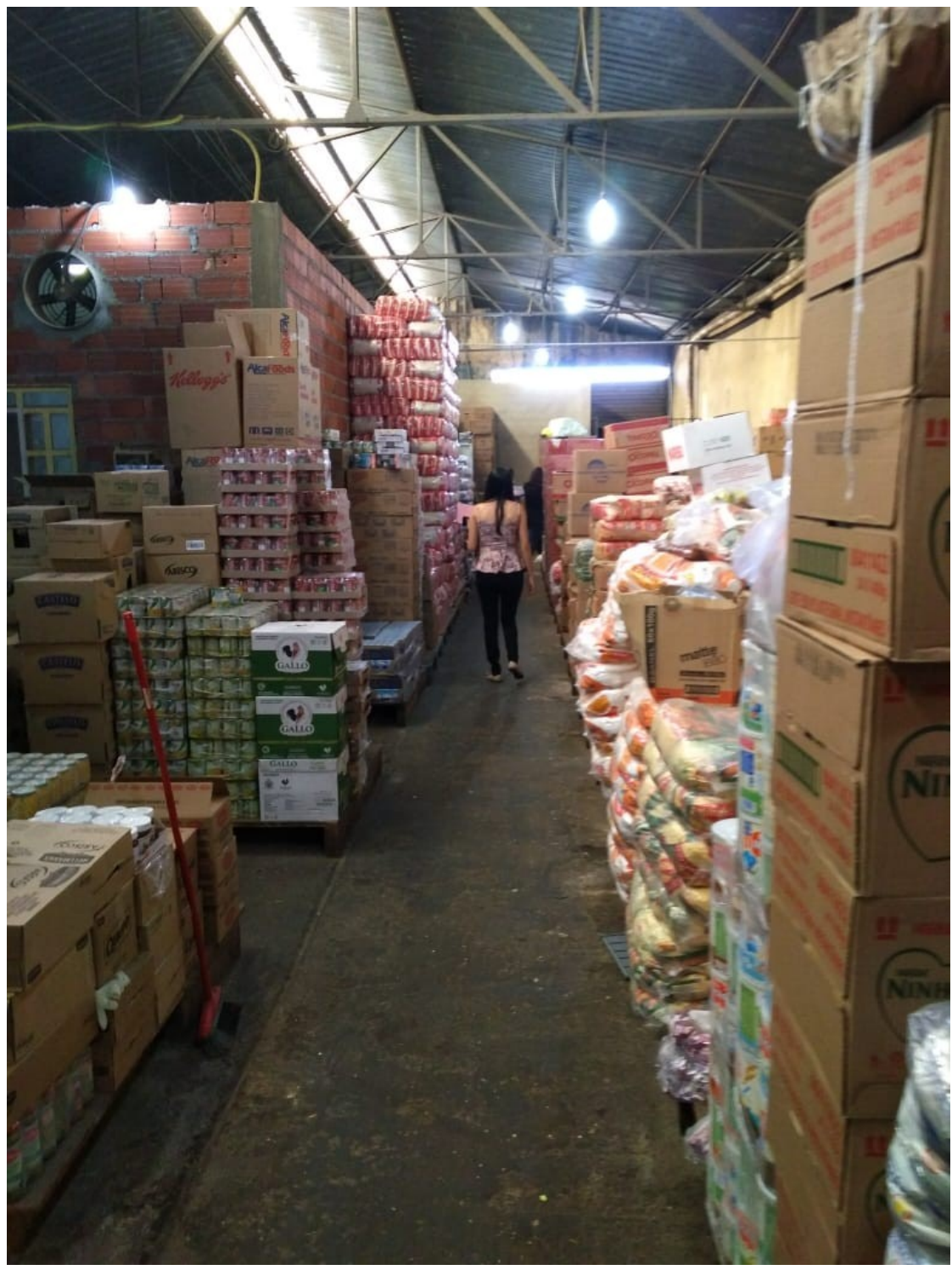

Fonte: Arquivo pessoal.

$\mathrm{Na}$ aula presencial seguinte, os estudantes foram mediados pelo docente a perceber esses problemas, propor soluções e orientados a operacionalizar os conteúdos técnicos construindo um protótipo (maquete) para apresentação dos resultados. Por ora como sugestão de estudo, uma vez que será no decorrer das visitas técnicas que os grupos irão definir o seu ponto de trabalho.

\section{4 - Considerações Finais}

Os desafios práticos desenvolvidos nos momentos presenciais devem ser produtivos 0 suficiente para que o estudante esteja vivenciando problemas reais, exercitando seu espírito reflexivo e crítico que, vale ressaltar, já estão presentes no perfil do aluno EaD, sobretudo, orientados pela Metodologia SENAI de Educação Profissional que conecta o conteúdo online ao exercício presencial, onde o resultado efetivo da solução de um 
problema depende das competências adquiridas ao longo do curso.

Esta característica proativa será muito importante para o exercício de sua profissão, quando terão de identificar eventuais gargalos e resolvê-los.

\section{5 - Referências}

BORGES, A. T. Novos rumos para o laboratório escolar de ciências. Caderno Brasileiro de Ensino de Física, v. 19, n. 3, p. 291-313, 2002.

FREIRE, P. Pedagogia do oprimido. Rio de Janeiro: Editora Paz e Terra, 1970.

FREIRE, P. Pedagogia da autonomia. São Paulo: Editora Paz e Terra, 1996.

FREIRE, Paulo. Pedagogia da Autonomia: Saberes Necessários a Prática Educativa. 25ํㅡㄹição. São Paulo: Paz e Terra S/A, 2002.

PERRENOUD, Philippe. Avaliação: da excelência à regulação das aprendizagens entre duas lógicas. Porto Alegre: Artmed, 1999.

POZO, J. I. Aprendizes e mestres. São Paulo: Artmed, 2001.

SANTOS, M. F. L. Práxis dos docentes dos cursos técnicos e tecnológicos e as demandas do mundo de trabalho: um olhar na relação teoria e prática - um foco no Theoprax. 128f. 2008. Dissertação (Mestrado em Teologia e Educação) - Escola Superior de Teologia, São Leopoldo, RS, 2008. 